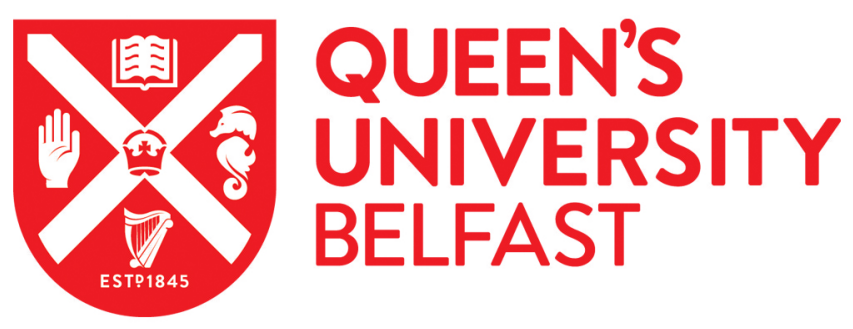

\title{
Laser irradiation of ocular tissues to enhance drug delivery
}

Singh, T. R. R., Adwan, S., Tekko, I., Soliman, K., \& Donnelly, R. F. (2021). Laser irradiation of ocular tissues to enhance drug delivery. International Journal of Pharmaceutics, 596, [120282].

https://doi.org/10.1016/j.ijpharm.2021.120282

Published in:

International Journal of Pharmaceutics

Document Version:

Peer reviewed version

Queen's University Belfast - Research Portal:

Link to publication record in Queen's University Belfast Research Portal

\section{Publisher rights}

Copyright 2021 Elsevier

This manuscript is distributed under a Creative Commons Attribution-NonCommercial-NoDerivs License

(https://creativecommons.org/licenses/by-nc-nd/4.0/), which permits distribution and reproduction for non-commercial purposes, provided the author and source are cited.

\section{General rights}

Copyright for the publications made accessible via the Queen's University Belfast Research Portal is retained by the author(s) and / or other copyright owners and it is a condition of accessing these publications that users recognise and abide by the legal requirements associated with these rights.

Take down policy

The Research Portal is Queen's institutional repository that provides access to Queen's research output. Every effort has been made to ensure that content in the Research Portal does not infringe any person's rights, or applicable UK laws. If you discover content in the Research Portal that you believe breaches copyright or violates any law, please contact openaccess@qub.ac.uk. 
Laser irradiation of ocular tissues to enhance drug delivery

Raghu Raj Singh Thakur ${ }^{\text {a*}}$, Samer Adwan ${ }^{\text {b }}$, Ismaiel Tekko ${ }^{\text {a }}$, Karim Soliman a , Ryan F Donnelly $^{\text {a }}$

a School of Pharmacy, Queens University Belfast, 97 Lisburn Road, Belfast, Northern Ireland, BT9 7BL.

${ }^{\mathrm{b}}$ Faculty of Pharmacy, Zarqa University, Zarqa 132222, Jordan.

*Corresponding author. Tel: +44 (0) 289097 5814. Email: r.thakur@qub.ac.uk.

* Corresponding Author

Dr Thakur Raghu Raj Singh

Reader in Pharmaceutics

School of Pharmacy

Queen's University Belfast

Medical Biology Centre

97 Lisburn Road

Belfast, BT9 7BL

United Kingdom

Tel: +44(0) 2890975814

Fax: +44 (0) 2890247794

Email:r.thakur@qub.ac.uk 


\section{Abstract}

Scleral and corneal membranes represent substantial barriers against drug delivery to the eye. Conventional hypodermic needles-based intraocular injections are clinically employed to overcome these barriers. This study, for the first time, investigated a non-invasive alternative to intraocular injections by laser irradiation of ocular tissues. The P.L.E.A.S.E. ${ }^{\circledR}$ laser device was applied on excised porcine scleral and corneal tissues, which showed linear relationships between depths of laser-created micropores and laser fluences at range $8.9-444.4 \mathrm{~J} / \mathrm{cm}^{2}$. Deeper and wider micropores were observed in scleral relative to corneal tissues. The permeation of rhodamine B and fluorescein isothiocyanate (FITC)-dextran were investigated through ocular tissues at different laser parameters (laser fluences $0-44.4 \mathrm{~J} / \mathrm{cm}^{2}$ and micropore densities 7.5 and 15\%). Both molecules showed enhanced permeation through ocular tissues on laser irradiation. Maximum transscleral permeation of the molecules was attained at laser fluence $8.9 \mathrm{~J} / \mathrm{cm}^{2}$ and micropore density $15 \%$. Transcorneal permeation of rhodamine B increased with increasing either laser fluence or micropore density, while that of FITC-dextran was not affected by either parameter. The transscleral water loss increased significantly after laser irradiation then returned to the baseline values within $24 \mathrm{~h}$, indicating healing of the lasercreated micropores. Laser irradiation is a promising technique to enhance intraocular delivery of both small and large molecule drugs.

\section{Keywords}

Scleral permeability; Corneal permeability; micropores; ocular delivery; optical coherence tomography, laser microporation. 


\section{Introduction}

Drugs which are topically administered to the eye suffer from low ocular bioavailability < $5 \%$, which is attributed to several anatomical and physiological barriers, including poor corneal and scleral permeability. These also include short residence time of drugs in the eye due to rapid tear turnover, nasolacrimal drainage, and conjunctival uptake to the systemic circulation $^{1,2}$. Intraocular injections using conventional hypodermic needles is routinely used for administration of both small molecules (corticosteroids) and biologics. However, their highly invasive nature causes considerable discomfort, pain, and occasional bleeding ${ }^{3,4}$. Permeation enhancing strategies such as chemical, physical and mechanical methods can provide an alternative to intraocular injections by increasing drug penetration through the corneal or scleral tissues. In particular, non-invasive methods such as iontophoresis ${ }^{5}$ (e.g., dexamethasone), high-frequency ultrasound/sonophoresis ${ }^{6}$ (e.g., tobramycin), and drug-loaded polymeric microneedles ${ }^{7}$ (e.g., amphotericin) can provide overarching advantages to its counterparts. Although these techniques were primarily investigated to enhance transdermal permeation of drugs ${ }^{8,9}$, they were extended for ocular applications demonstrating enhanced corneal and scleral permeation of selected drug molecules.

Fractional laser irradiation is a non-invasive technique for enhancement of transdermal drug permeation via transient perforation of a localized area in the stratum corneum ${ }^{10,11}$. Nelson et al. reported higher permeation of small and large molecule drugs through laser-irradiated skin relative to tape-stripped skin, which implies that laser irradiation increases transdermal permeability by various mechanisms ${ }^{12}$. Three mechanisms were reported to be involved in laser-assisted drug delivery, namely, (a) ablation or perforation of surface tissues, (b) generation of photomechanical waves, and (c) photothermal effects, which collectively disrupt the barrier function of the tissues ${ }^{13}$. The predominance of any of these mechanisms depends on laser parameters, including wavelength, power, and pulse duration. For instance, erbium-doped 
yttrium aluminium garnet laser (Er: YAG) has a mid-infrared wavelength $(2940 \mathrm{~nm})$ which is strongly absorbed by water, resulting in localized water vaporization inside tissues and subsequently confined tissue ablation, with minimum thermal damage to adjacent tissues ${ }^{14-16}$. Using a similar mid-infrared laser of wavelength $2790 \mathrm{~nm}$, Nelson et al. showed that there was a linear correlation between the number of pulses and the depth of the created micropores ${ }^{12}$. Pantec Biosolutions developed precise laser epidermal system (P.L.E.A.S.E ${ }^{\circledR}$ ), which has wide range of applications in transdermal delivery due to its ability to create micropores with controlled depth, density, and area ${ }^{17}$. For example, Bachhav et al. reported the presence of linear correlation between the cumulative permeation of diclofenac through porcine ear skin and the laser induced micropores produced by P.L.E.A.S.E. ${ }^{\circledR}$ device $^{18}$. Similarly, Lee et al. investigated the permeability of fluorescein isothiocyanate (FITC)-labelled dextran through mouse and porcine skin after laser application by P.L.E.A.S.E. ${ }^{\circledR}$ device and reported an increased fluorescence in the skin after laser treatment compared to the control ${ }^{19}$.

On the other hand, controlled laser irradiation is widely used for medical applications in the eye, such as laser photocoagulation surgeries which are used for the treatment of age-related macular degeneration ${ }^{20}$, open-angle glaucoma ${ }^{21}$, and diabetic retinopathy ${ }^{20}$. Furthermore, laser ablation is used in vision correction ${ }^{22}$ and cataract surgeries ${ }^{23}$. Laser irradiation was also applied in rabbit eyes to control the release of dexamethasone from intrachoroidal implant ${ }^{24}$, and for activation of intraocularly injected virus-like particles for treatment of uveal melanoma $^{25}$.

Although laser irradiation has not yet investigated in ocular drug delivery, the wide ocular applications of laser represent good standing for the technology with respect its safety and feasibility as drug permeation-enhancer in the eye, provided that laser parameters are finely controlled. In this project, for the first time, fractional Er:YAG P.L.E.A.S.E. ${ }^{\circledR}$ was investigated for its potential to enhance drug permeation through corneal or the scleral tissues. Rhodamine 
B (479 Da, Log P 1.8) was used as a model hydrophobic molecule; FITC-dextran (150 kDa, Log P -7.1) an d FITC-labelled bovine serum albumin (BSA) (66.5 kDa) were used as a model for a large molecules.

\section{Experimental section}

\subsection{Materials}

Rhodamine B and FITC-BSA was purchased from Sigma-Aldrich (Steinheim, Germany). Phosphate buffer saline tablets (PBS, pH 7.4) was purchased from Oxoid (Hampshire, England). Fluorescein isothiocyanate-dextran Mw $150 \mathrm{kDa}$ was purchased from TdB Consultancy AB (Uppsala, Sweden). Acetonitrile was purchased from Sigma-Aldrich (Gillingham, Dorset). Optimum cutting temperature compound was purchased from Sakura Fine technical (Tokyo, Japan). Other reagents not mentioned were of analytical grade and used as received. All aqueous solutions were prepared with ultrapure water $(18.2 \mathrm{M} \Omega \cdot \mathrm{cm}$, Millipore).

\subsection{Laser irradiation of ocular tissues}

Ocular tissues were prepared by removing the adherent muscle tissue from extracted porcine eye bulbs, and circumferentially cutting the anterior segment of the eye behind the limbus. The vitreous humor was removed, and both the anterior sclera and corneal tissues were isolated by removal of the underling tissues. The isolated tissues were kept in phosphate buffer saline (PBS, $\mathrm{pH} 7.4$ ) containing $0.05 \%$ sodium azide and used within $24 \mathrm{~h}$ of extraction.

The laser was applied to the extracted corneal and scleral porcine tissues using P.L.E.A.S.E. ${ }^{\circledR}$ device (Pantec Biosolutions, Ruggell, Liechtenstein), operated at power $0.9 \mathrm{~W}$ and frequency 
$200 \mathrm{~Hz}$, to produce micropore densities of 7.5 and $15 \%$ equivalent to 450 and 900 micropores, respectively. The laser fluences applied were $2.8,8.9,44.4,88.9,222.2$, and $444.4 \mathrm{~J} / \mathrm{cm}^{2}$.

\subsection{Characterization of laser-created micropores in the ocular tissues}

Optical coherence tomography (OCT) was used to visualize the micropores created within $1 \mathrm{~h}$ after laser treatment. The swept-source Fourier domain OCT system has a laser center wavelength of $1305 \pm 15 \mathrm{~nm}$, facilitating real-time high-resolution imaging of the upper ocular tissue layers (7.5 $\mu \mathrm{m}$ lateral and $10 \mu \mathrm{m}$ vertical resolution). 2D cross-sectional scans were done for the ocular tissues at frame rate of $15 \mathrm{scans} / \mathrm{s}$ and scan width of $2.0 \mathrm{~mm}$. The micropores were characterized in terms of their depths and widths, using Image ${ }^{\circledR}$ software. The results were reported as mean $\pm \mathrm{SD}(\mathrm{n}=10)$. Furthermore, the laser-treated ocular tissues were imaged under scanning electron microscopy (SEM) at magnification power 100X.

Scleral and corneal tissues were also visualized using a Leica MZ6 dissection microscope fitted with a Nikon Coolpix 950 digital camera and TM3030 table top scanning electron microscope in order to evaluate the tissue effects of laser treatment.

\subsection{In vitro permeation studies through ocular tissues}

The in vitro permeation studies were conducted on the excised corneal and scleral tissues before and after laser irradiation using modified Franz-type diffusion cells in five replicates. In vitro permeation of Rhodamine B and FITC-dextran (150 kDa) were investigated through non-irradiated and laser-irradiated corneal and scleral tissues at fluences of 2.8, 8.9, and $44.4 \mathrm{~J} / \mathrm{cm}^{2}$ with a micropore density of $7.5 \%$. Furthermore, the effect of micropore density (7.5 and 15\%) was studied at a fixed laser fluence of $8.9 \mathrm{~J} / \mathrm{cm}^{2}$. The transscleral permeation of FITC-BSA was investigated through the scleral tissues before and after laser irradiation at 
selected parameters i.e., laser fluence of $8.9 \mathrm{~J} / \mathrm{cm}^{2}$ and micropore density of $15 \%$. The receptor compartments of the Franz cells were filled with $5 \mathrm{~mL}$ PBS containing $0.05 \%$ sodium azide, and stirred at $50 \mathrm{rpm}$ and $37^{\circ} \mathrm{C}$. The ocular tissues were hydrated in PBS at $37^{\circ} \mathrm{C}$ for $2 \mathrm{~h}$, then mounted on the receptor compartments. After temperature equilibration, $200 \mu \mathrm{L}$ solutions of either rhodamine B, FITC-Dextran, or FITC-BSA were added to the donor compartments, and the sampling arms and donor compartments were sealed using Parafilm ${ }^{\circledR}$. After $24 \mathrm{~h}$, samples of $200 \mu \mathrm{L}$ volume were removed from the receptor compartments and analyzed for the concentrations of the permeated molecules using fluorescence plate reader. For assay of rhodamine $\mathrm{B}$, the excitation and emission wavelengths were set at 544 and $620 \mathrm{~nm}$, while they were set at 485 and $520 \mathrm{~nm}$, for assay of FITC-dextran and FITC-BSA. Drug permeation was calculated as $\%$ of the amount of drug added to the donor compartments.

\subsection{Drug distribution within ocular tissues}

The scleral tissues that were exposed to laser of fluence $8.9 \mathrm{~J} / \mathrm{cm}^{2}$ and micropore density $15 \%$ were selected for further investigation of drug distribution relative to non-irradiated tissues. After completing the in vitro permeation studies (24 h), the selected tissues were placed into sample blocks containing optimum cutting temperature compound and were snap-frozen with liquid nitrogen to $-20^{\circ} \mathrm{C}$. The tissue samples were then sectioned into $50 \mu \mathrm{m}$ thick pieces using a cryostat microtome and examined by confocal laser scanning microscope (CLSM).

\subsection{Ocular tissues recovery}

The recovery of the ocular tissues following laser irradiation was assessed by measuring the transscleral water loss (TSWL) or transcorneal water loss (TCWL) of the ocular tissues irradiated at laser fluences 8.9 and $44.4 \mathrm{~J} / \mathrm{cm}^{2}$ and micropore density $7.5 \%$ relative to the nonirradiated ones. Six replicates of each of the laser-irradiated and non-irradiated ocular tissues 
were hydrated in $\mathrm{PBS}$ at $37^{\circ} \mathrm{C}$ for $2 \mathrm{~h}$, and then mounted on the receptor compartments of modified Franz-type diffusion cells filled with $5 \mathrm{~mL}$ PBS / 0.05\% sodium azide and stirred at $50 \mathrm{rpm}$ and $37^{\circ} \mathrm{C}$. Water loss was measured at time points of $0,6,24$, and $48 \mathrm{~h}$ by mounting VapoMeter (Delfin Technologies; Kuopio, Finland) on the ocular tissues for $20 \mathrm{~s}$. TCWL and TSWL were expressed as $\mathrm{g} / \mathrm{m}^{2} . \mathrm{h}$ and was plotted $v s$. time.

The scleral tissues recovery was also investigated by OCT measurement of micropores depths and diameters after laser-irradiation at fluence of $44.4 \mathrm{~J} / \mathrm{cm}^{2}$ and micropore density of $7.5 \%$. The laser-irradiated scleral tissues were soaked in PBS / 0.05\% w/v sodium azide, and kept in a shaking incubator at $50 \mathrm{rpm}$ and $37^{\circ} \mathrm{C}$. At time points of $0,24,48$ and $72 \mathrm{~h}$, the scleral tissues were removed from the soaking medium and subjected to OCT imaging using the same abovementioned procedure. Micropores depths and widths were measured using Image $\mathbb{\circledR}$ software, expressed as mean $\pm \mathrm{SD}(\mathrm{n}=10)$, and plotted $v s$. time.

\subsection{Statistical analysis}

GraphPad Prism ${ }^{\circledR}$ version 5.0 GraphPad Software was used to perform statistical analysis. Where appropriate, a Kruskal-Wallis test with post-hoc Dunn's test was used for comparison of multiple groups, with a Mann-Whitney U test performed for comparison of two groups. Data were expressed as means \pm standard deviation. In all cases, statistical significance was defined at the standard $5 \%$ level.

\section{Results}

\subsection{Characterization of laser-created micropores in the ocular tissues}


OCT and SEM imaging showed pore formation in the ocular tissues at laser fluences of 8.9 and $44.4 \mathrm{~J} / \mathrm{cm}^{2}$, whereas exposure to laser of fluences $\geq 88.9 \mathrm{~J} / \mathrm{cm}^{2}$ led to severe disruption of the ocular tissues (Fig. 1-2). Both micropores depths and widths formed in the scleral tissue were greater than those formed in the corneal tissues at each applied fluence. The depths of the created micropores within the ocular tissues increased linearly with increasing laser fluence in the range of $2.8-444.4 \mathrm{~J} / \mathrm{cm}^{2}$ at micropore density of $7.5 \%$ (Fig. 3), while the widths of the created micropores were linearly correlated to the log laser fluence.

\subsection{In vitro permeation studies through ocular tissues}

In the non-irradiated ocular tissues, the \% permeation values of rhodamine B were 4.5 and 15.6-fold those of FITC-dextran in scleral and corneal tissues, respectively (Fig. 4). Comparing the permeation of the molecules through non-irradiated corneal and scleral tissues, rhodamine B showed higher permeation through the corneal tissues, whereas FITC-dextran exhibited higher permeation through scleral tissues. At micropore density of $7.5 \%$, rhodamine B showed its maximum transscleral permeation $(45.8 \pm 9.1 \%)$ at laser fluence $8.9 \mathrm{~J} / \mathrm{cm}^{2}$, which was significantly higher than the non-irradiated scleral tissue $(16.1 \pm 3.8 \%)$ at $p \leq 0.05$. Increasing the laser fluence $>8.9 \mathrm{~J} / \mathrm{cm}^{2}$ did not increase rhodamine $\mathrm{B} \%$ transscleral permeation. Increasing the micropore density until $15 \%$ at laser fluence $8.9 \mathrm{~J} / \mathrm{cm}^{2}$, resulted in significant increase of rhodamine B transscleral permeation to $77.5 \pm 15.8 \%(p \leq 0.05)$. Similarly, FITC-dextran showed its maximum transscleral permeation $(21.9 \pm 6.9 \%)$ at laser fluence $8.9 \mathrm{~J} / \mathrm{cm}^{2}$ and micropore density $15 \%$, yet, we did not detect significant increase in permeation on increasing micropore density from 7.5 to $15 \%(p>0.05)$. However, the transscleral permeation of FITC-dextran did not show any significant improvement on increasing micropore density from 7.5 to $15 \%(p>0.05)$. FITC-BSA did not show detectable permeation through the non-irradiated scleral tissues within $24 \mathrm{~h}$, whereas it showed $4.6 \%$ 
permeation through the scleral tissues irradiated with laser of fluence $8.9 \mathrm{~J} / \mathrm{cm}^{2}$ and micropore density $15 \%$.

On the other hand, at micropore density of $7.5 \%$, rhodamine B showed its maximum transcorneal permeation $(41.2 \pm 7.6 \%)$ at laser fluence $44.4 \mathrm{~J} / \mathrm{cm}^{2}$. Exposing the corneal tissues to laser of micropore density $15 \%$ and fluence of $8.9 \mathrm{~J} / \mathrm{cm}^{2}$ resulted in rhodamine $\mathrm{B}$ transcorneal permeation of $42.3 \pm 2.6 \%$, which was significantly higher than that obtained using laser of micropore density $7.5 \%$ at the same fluence $(p \leq 0.05)$. In contrast, the transcorneal permeation of FITC-dextran did not show significant increase on increasing the laser fluence $>2.8 \mathrm{~J} / \mathrm{cm}^{2}$ or increasing the micropore density $>7.5 \%(\mathrm{p}>0.05)$. The maximum transcorneal permeation of FITC-dextran was obtained at laser fluence $8.9 \mathrm{~J} / \mathrm{cm}^{2}$ and micropore density of $15 \%(6.4 \pm 3.1 \%)$.

\subsection{Drug distribution within ocular tissues}

The CLSM showed higher permeation of rhodamine B, FITC-dextran, and FITC-BSA in the laser-irradiated scleral tissues relative to the non-irradiated ones (Figure 5).

\subsection{Ocular tissues recovery}

As shown in Figure 6, TSWL increased significantly $(p \leqslant 0.05)$ by $44-51 \%$ after laser irradiation at fluences 8.9 and $44.4 \mathrm{~J} / \mathrm{cm}^{2}$. TSWL returned to baseline within $24 \mathrm{~h}$, with associated decrease in micropores depths and widths measured under OCT (Fig. 7). On the other hand, TCWL showed a significant increase $(p \leqslant 0.05)$ by $70-78 \%$ after laser irradiation at fluences 8.9 and $44.4 \mathrm{~J} / \mathrm{cm}^{2}$, yet, water loss from corneal tissues did not return back to the baseline values after $48 \mathrm{~h}$ (Fig. 6). 


\section{Discussion}

This study showed that laser-irradiation enhanced permeation of both small and large molecules through corneal and scleral tissues. Permeation of the molecules through ocular tissues was affected by several factors including the physicochemical properties of the molecules, type of the tissue (cornea $v s$. sclera), as well as laser parameters. For instance, the small molecule hydrophobic rhodamine B showed higher permeation through both corneal and scleral tissues relative to the large molecule hydrophilic FITC-dextran. Furthermore, the permeation of rhodamine B and FITC-dextran through non-irradiated corneal tissues relative to scleral tissues complied with the findings of Prausnitz and Noonan literature analysis, which showed that small molecule hydrophobic drugs tended to show higher permeation through corneal tissues, whereas large molecule hydrophilic drugs generally showed higher permeation through scleral tissues ${ }^{26}$. At same laser parameters, the micropores created in the scleral tissues were deeper and wider than those created in the corneal tissues, which may be attributed to the more ordered arrangement of the collagen fibrils in corneal tissues (Fig. 8) and the subsequent higher resistance for laser-induced ablation ${ }^{27}$.

The transscleral permeation of both rhodamine B and FITC-dextran showed maximum increase at laser fluence $8.9 \mathrm{~J} / \mathrm{cm}^{2}$, which may be due to the photothermal effects causing blockage of the micropores at higher fluences. On the other hand, increasing micropore density from $7.5 \%$ to $15 \%$ resulted in increasing the transscleral permeation of rhodamine B but not FITC-dextran, which may be attributed to the higher Mw of the latter. The transcorneal permeation did not follow the same pattern, where rhodamine B showed higher permeation on increasing either laser fluence or micropore density, while the permeation of FITC-dextran was not affected by either. This may be explained by the effect of different laser fluences on different corneal layers. While the corneal epithelium presents permeation barrier to all types of drugs, the underlying stroma and endothelium mainly control the permeation of small 
molecule hydrophobic drugs ${ }^{26}$. At relatively low laser fluences $\leq 8.9 \mathrm{~J} / \mathrm{cm}^{2}$, the corneal epithelium was ablated which led to increased permeation of both small molecule hydrophobic rhodamine B and large hydrophilic FITC-dextran. At higher laser fluences, the laser ablative effect may have extended to deeper layers of the cornea which affected the permeation of rhodamine B to a greater extent. This also can be attributed to the lower response of FITCdextran permeability to laser parameters due to its large Mw. The lack of recovery of TCWL to baseline within $48 \mathrm{~h}$ indicates non-healing of the corneal micropores. In contrast, the recovery of TSWL to baseline within $24 \mathrm{~h}$ is evidence of healing of the scleral micropores, which was confirmed by decrease of micropore dimensions observed under OCT.

Several studies in the literature reported analogous results on applying P.L.E.A.S.E. ${ }^{\circledR}$ device on skin to enhance transdermal drug delivery. Although the differences in histological structure between stratum corneum and ocular tissues invalidate comparison between laserassisted transdermal and ocular drug delivery, the results obtained from previous transdermal studies can support the conclusions drawn from the current study, particularly in absence of previous similar work on laser-assisted ocular drug delivery. Bachhav et al. applied P.L.E.A.S.E. ${ }^{\circledR}$ device to enhance the transdermal permeation of lidocaine (Mw 234, Log P 2.4), where the authors reported enhanced transdermal permeation at low laser fluences and micropore densities, yet they did not observe any significant difference in permeation at laser fluences $22.7-135.9 \mathrm{~J} / \mathrm{cm}^{2}$ or micropore densities $>7.5 \%$, which was attributed to probable drug depletion ${ }^{17}$. Similarly, Lee et al. used P.L.E.A.S.E. ${ }^{\circledR}$ device to enhance the transdermal permeation of 5-aminolevulinic acid (Mw 131, Log P -1.5) at fluence $2 \mathrm{~J} / \mathrm{cm}^{2}$ which produced partial ablation of the stratum corneum ${ }^{28}$. The authors reported that increasing the number of laser applications did not increase the permeation significantly and concluded that laser enhanced the transdermal permeation by other mechanisms beside the direct ablation of the superficial skin layer. Similar to TSWL and TCWL, the transepidermal water loss (TEWL) has 
been commonly investigated as a measure of the skin barrier function. Machado et al. validated the hypothesis that TEWL is directly proportional to the reciprocal of the diffusional permeation path length of the stratum corneum ${ }^{29}$. Lee et al. also investigated the TEWL as a measure of the integrity of the skin barrier function after laser application ${ }^{28}$.

FITC-BSA was used as a model for anti-VEGF proteins conventionally administered as intravitreal injections, hence, FITC-BSA permeability was investigated only in scleral tissues. The transscleral permeation of FITC-BSA was investigated only at laser fluence 8.9 $\mathrm{J} / \mathrm{cm}^{2}$ and micropore density $15 \%$, as these were the parameters showing highest permeation for both FITC-dextran and rhodamine B. The same laser parameters were also selected for CLSM investigation of distribution of different molecules in scleral tissues. Transcorneal and transscleral permeation of rhodamine B and FITC-dextran were investigated at laser fluences $\leq 44.4 \mathrm{~J} / \mathrm{cm}^{2}$, as higher fluences showed disruption of ocular tissues, and would be patient inconvenient.

In conclusion, both small molecule hydrophobic and large molecule hydrophilic model molecules showed enhanced permeation across scleral and corneal tissues upon fractional laser irradiation using P.L.E.A.S.E. ${ }^{\circledR}$ device. The optimum laser fluence and micropore density differed according to the physicochemical properties of the drug and the irradiated ocular tissues (cornea vs. sclera). The laser-created micropores showed recovery only in the scleral tissues under the study conditions. Fractional laser irradiation is a promising technique to enhance corneal and scleral permeability of different drugs, yet further in vivo preclinical studies should be carried out.

\section{Acknowledgements}

We acknowledge Pantec Biosolutions for lending the P.L.E.A.S.E. ${ }^{\circledR}$ device for this project. Dr. Adwan received $\mathrm{PhD}$ funding from Zarqa University, Jordan. 


\section{References}

1. Gaudana, R., Ananthula, H. K., Parenky, A. \& Mitra, A. K. Ocular drug delivery. AAPS J. 12, 348-360 (2010).

2. Patel, A., Cholkar, K., Agrahari, V. \& Mitra, A. K. Ocular drug delivery systems: An overview. World J. Pharmacol. 2, 47-64 (2013).

3. Falavarjani, K. G. \& Nguyen, Q. D. Adverse events and complications associated with intravitreal injection of anti-VEGF agents: a review of literature. Eye (Lond). 27, 787794 (2013).

4. Schwartz, S. G., Flynn Jr, H. W. \& Scott, I. U. Intravitreal corticosteroids in the management of diabetic macular edema. Curr. Ophthalmol. Rep. 1, 10.1007/s40135013-0015-3 (2013).

5. Patane, M. A. et al. Ocular iontophoresis of EGP-437 (dexamethasone phosphate) in dry eye patients: results of a randomized clinical trial. Clin. Ophthalmol. 5, 633-643 (2011).

6. Nabili, M. et al. Ultrasound-enhanced delivery of antibiotics and anti-inflammatory drugs into the eye. Ultrasound Med. Biol. 39, 638-646 (2013).

7. Thakur Singh, R. R. et al. Minimally invasive microneedles for ocular drug delivery. Expert Opin. Drug Deliv. 14, 525-537 (2017).

8. Donnelly, R. F. et al. Hydrogel-forming microneedle arrays for enhanced transdermal drug delivery. Adv. Funct. Mater. 22, 4879-4890 (2012).

9. Larrañeta, E., Lutton, R. E. M., Woolfson, A. D. \& Donnelly, R. F. Microneedle arrays as transdermal and intradermal drug delivery systems: Materials science, manufacture and commercial development. Mater. Sci. Eng. R Reports 104, 1-32 (2016). 
10. Fujimoto, T., Ito, M., Ito, S. \& Kanazawa, H. Fractional laser-assisted percutaneous drug delivery via temperature-responsive liposomes. J. Biomater. Sci. Polym. Ed. 28, 679689 (2017).

11. Ali, F. R. \& Al-Niaimi, F. Laser-assisted drug delivery in dermatology: from animal models to clinical practice. Laser Med. Sci. 31, 373-381 (2016).

12. Nelson, J. S. et al. Mid-infrared laser ablation of stratum corneum enhances in vitro percutaneous transport of drugs. J. Invest. Dermatol. 97, 874-879 (1991).

13. Lin, C.-H., Aljuffali, I. A. \& Fang, J.-Y. Lasers as an approach for promoting drug delivery via skin. Expert Opin. Drug Deliv. 11, 599-614 (2014).

14. Lee, W.-R. et al. Erbium:YAG laser enhances transdermal peptide delivery and skin vaccination. J. Control. Release 128, 200-208 (2008).

15. Riggs, K., Keller, M. \& Humphreys, T. R. Ablative laser resurfacing: high-energy pulsed carbon dioxide and erbium:yttrium-aluminum-garnet. Clin. Dermatol. 25, 462473 (2007).

16. Durán, S. \& Zato, M. Erbium:YAG laser emulsification of the cataractous lens. $J$. Cataract Refract. Surg. 27, 1025-1032 (2001).

17. Bachhav, Y. G. et al. Effect of controlled laser microporation on drug transport kinetics into and across the skin. J. Control. Release 146, 31-36 (2010).

18. Bachhav, Y. G., Heinrich, A. \& Kalia, Y. N. Using laser microporation to improve transdermal delivery of diclofenac: Increasing bioavailability and the range of therapeutic applications. Eur. J. Pharm. Biopharm. 78, 408-414 (2011).

19. Lee, W.-R. et al. Laser-assisted topical drug delivery by using a low-fluence fractional laser: Imiquimod and macromolecules. J. Control. Release 153, 240-248 (2011). 
20. Figueroa, M., Schocket, L. S., DuPont, J., Metelitsina, T. I. \& Grunwald, J. E. Effect of laser treatment for dry age related macular degeneration on foveolar choroidal haemodynamics. Br. J. Ophthalmol. 88, 792-795 (2004).

21. Osman, E. Laser refractive surgery in glaucoma patients. Saudi J. Ophthalmol. Off. J. Saudi Ophthalmol. Soc. 25, 169-173 (2011).

22. Tiwari, N. N., Sachdev, G. S., Ramamurthy, S. \& Dandapani, R. Comparative analysis of visual outcomes and ocular aberrations following wavefront optimized and topography-guided customized femtosecond laser in situ keratomileusis for myopia and myopic astigmatism: A contralateral eye study. Indian J. Ophthalmol. 66, 1558-1561 (2018).

23. Chen, H., Hyatt, T. \& Afshari, N. Visual and refractive outcomes of laser cataract surgery. Curr. Opin. Ophthalmol. 25, 49-53 (2014).

24. Murata, M., Sanbe, A., Lee, J. W. \& Nishigori, H. Laser-induced intrachoroidal dexamethasone drug delivery system to posterior eye segment. Invest. Ophthalmol. Vis. Sci. 54, 8317-8324 (2013).

25. Kines, R. C. et al. An infrared dye-conjugated virus-like particle for the treatment of primary uveal melanoma. Mol. Cancer Ther. 17, 565 LP-574 (2018).

26. Prausnitz, M. R. \& Noonan, J. S. Permeability of cornea, sclera, and conjunctiva: A literature analysis for drug delivery to the eye. J. Pharm. Sci. 87, 1479-1488 (1998).

27. Komai, Y. \& Ushiki, T. The three-dimensional organization of collagen fibrils in the human cornea and sclera. Invest. Ophthalmol. Vis. Sci. 32, 2244-2258 (1991).

28. Lee, W.-R. et al. Fractional laser as a tool to enhance the skin permeation of 5aminolevulinic acid with minimal skin disruption: A comparison with conventional 
erbium:YAG laser. J. Control. Release 145, 124-133 (2010).

29. Machado, M., Salgado, T. M., Hadgraft, J. \& Lane, M. E. The relationship between transepidermal water loss and skin permeability. Int. J. Pharm. 384, 73-77 (2010). 


\section{Competing interests}

The authors declare no competing interests.

\section{Data availability}

All data generated or analyzed during this study are included in this published article. 


\section{Figure legends}

Figure 1. OCT and SEM images of scleral tissue before and after laser treatment at different fluences $\left(\mathrm{J} / \mathrm{cm}^{2}\right)$ and at a micropore density of $7.5 \%$. Scale bars for OCT images is $1 \mathrm{~mm}$.

Figure 2. OCT and SEM images of corneal tissue before and after laser treatment at different fluences $\left(\mathrm{J} / \mathrm{cm}^{2}\right)$ and at a micropore density of $7.5 \%$. Scale bars for OCT images is $1 \mathrm{~mm}$.

Figure 3. (a) Depths and (b) widths of the laser-created micropores at different laser fluences $($ mean $\pm \mathrm{SD}, \mathrm{n}=10)$.

Figure 4. Transscleral and transcorneal permeation of rhodamine B and FITC-dextran at (a) different laser fluences at micropore density $7.5 \%$ and (b) different micropore densities at laser fluence $8.9 \mathrm{~J} / \mathrm{cm}^{2}($ mean $\pm \mathrm{SD}, \mathrm{n}=5)$.

Figure 5. Transscleral distribution of rhodamine B, FITC-Dextran, and FITC-BSA in nonirradiated and laser-irradiated scleral tissues at fluence $8.9 \mathrm{~J} / \mathrm{cm}^{2}$ and micropore density $15 \%$. Figure 6. Water loss from non-irradiated and laser-irradiated (a) scleral and (b) corneal tissues $($ mean $\pm \mathrm{SD}, \mathrm{n}=6)$.

Figure 7. (a) Micropore dimensions (mean $\pm \mathrm{SD}, \mathrm{n}=10$ ) and (b) OCT images of scleral tissues after laser treatment at fluence $44.4 \mathrm{~J} / \mathrm{cm}^{2}$ and micropore density $7.5 \%$. Scale bars for OCT images is $1 \mathrm{~mm}$.

Figure 8. SEM images of collagen fibril arrangement in the (a) cornea and (b) sclera. (27). 
